\title{
Measuring nutrient fluxes across the sediment-water interface using benthic chambers
}

\author{
J. M. Forja ${ }^{1, *}$, A. Gómez-Parra ${ }^{2, * *}$ \\ ${ }^{1}$ Departamento de Química Física, Facultad de Ciencias del Mar, Universidad de Cádiz, Campus Río San Pedro, s/n, \\ E-11510 Puerto Real (Cádiz), Spain \\ ${ }^{2}$ Departamento de Oceanografía, Instituto de Ciencias Marinas de Andalucía (C..S.I.C.), Campus Río San Pedro, s/n, \\ E-11510 Puerto Real (Cádiz), Spain
}

\begin{abstract}
This paper presents a simple model to determine the benthic fluxes of matter across the sediment-water interface when a benthic chamber is used. The model is based on accepting that the limiting step for the overall rate of transfer while the chamber is in position is the diffusion through the diffusive boundary layer (DBL) overlying the sediment, and it assumes that this rate is necessarily affected by the procedure employed to measure the flux. Alteration of the benthic fluxes due to the action of macrofaund is included in the model and, operatively, is expressed in terms of a reduction in the thickness of the DBL between the sediment and the water. If the diffusive fluxes are determined simultaneously with the benthic chamber experiments, a value can be estimated for the thickness of the 'stagnant film'. Owing to the assumptions made and to the micro-heterogeneities of the sediment, this thickness can be considered to have both an operative and a statistical meaning, with respect to the entire surface area covered by the chamber. The values calculated in the Bay of Cádiz (SW Spain) vary between 0.36 and $0.71 \mathrm{~mm}$, which are in agreement with measurements of this film made by different techniques in other littoral ecosystems. However, the values of the in situ fluxes estimated using this model and by other established procedures described in the literature can differ by more than $50 \%$, for the same experiment, in strongly irrigated zones.
\end{abstract}

KEY WORDS: Benthic chamber · Benthic regeneration - Nutrient fluxes - Diffusive fluxes - Macrofaunal irrigation. Sediment-water interface $\cdot$ Coastal ecosystem

\section{INTRODUCTION}

The regeneration of nutrients originating from the microbial degradation of organic material constitutes one of the main processes involved in sustaining primary productivity in littoral ecosystems (e.g. Billen 1978, Boynton et al. 1980, Callender \& Hammond 1982, Hopkinson 1987). Such places are often subjected to powerful 'inputs' of autochthonous and allochthonous organic matter and are usually relatively shallow. This results in the rapid sedimentation of particulate organic material and therefore the regeneration takes place preferentially within the sediment.

\footnotetext{
•E-mail: jesus.forja@uca.es

- Present address: Departamento de Química Física, Facultad de Ciencias del Mar, Universidad de Cádiz, Campus Río San Pedro, s/n, E-11510 Puerto Real (Cádiz), Spain
}

Measurement of the benthic regeneration of nutrients requires the incubation of a known area of sediment in contact with a known volume of supernatant water; after this phase, the variations in concentration of the species under study must be determined over a certain period of time (ranging from hours to weeks). In comparison with the incubation of undisturbed cores in the laboratory, measurements made in situ using benthic chambers offer several advantages; e.g. (1) the sediment surface area delimited by the chamber can be relatively large, thus minimizing the effect of the micro-heterogeneity usually found in the constitution of coastal sediments; (2) manipulation of the sediment is avoided, and incubation takes place under the original environmental conditions; and (3) the contribution of the benthic infauna to fluxes across the sedimentwater interface is taken into account. Since this measurement technique was first carried out, by Rowe et 
al. (1975), it has been used in a wide variety of marine environments, from intertidal zones (Asmus 1986, Matsukawa et al. 1987) to ocean depths of more than $6000 \mathrm{~m}$ (Smith et al. 1983).

However, despite the large number of studies in which benthic chambers have been used, no uniformity in their design has been achieved. The shape (e.g. cylindrical, hemispherical, semi-ellipsoid), the size, the material of construction, its degree of transparency, the method by which and degree to which the incubated water is agitated, the procedures used for chamber anchorage and to collect samples from them, as well as other features affecting their operation, differ sharply (e.g. Malan \& McLachlan 1991).

This lack of agreement also extends to the method of calculating the fluxes from the measured variations in concentration $(C)$ in the interior of the chamber over time $(t)$. In most of the literature, when both variables show an approximately linear relationship, the flux is usually calculated from the slope of the regression line, taking into account the dimensions of the chamber (e.g. Callender \& Hammond 1982, Fisher et al. 1982, Doering et al. 1987). This implies the assumption that the rate of flux across the sediment-water interface does not change during the period of incubation.

The existence of a non-linear relationship between $C$ and $t$ has been described both for incubations of 'cores' (Elderfield et al. 1981) and for benthic chambers (Kautsky \& Wallentinus 1980, Devol 1987). Nonlinearity cannot be attributed to the consumption or production of nutrients in the incubated water, since both terms are relatively small and, in addition, tend to cancel each other out (Fisher et al. 1982, GómezParra \& Forja 1993).

Working with chambers, Devol (1987) found that the curvature shown by the values for the concentration inside the chamber over the course of the incubation period could not be explained by the inevitable dilution occurring when samples are taken from the chamber. It is certain that such dilution occurs, but even if the experimental values obtained for the concentration are corrected by means of a mass balance, taking into account the concentration of the water from the exterior that enters the chamber, there is still a lack of linearity.

The use of chambers necessarily implies that an increase or decrease takes place in the concentration of the substance being studied inside the chamber, since it is through this variation that the fluxes are determined. This must modify the original gradients that exist between the sediment and the water column, so that the fluxes measured inside the chamber must be different from the natural fluxes. Obviously, from the dimensions involved, this problem is very far from the quantum indeterminism, but it is evident that the system of measurement itself alters in an appreciable way the value of the variable whose measurement is sought.

Various solutions have been proposed to overcome this problem. Thus, Hall et al. (1989) describe a 1-dimensional transport-reaction model to calculate the oxygen uptake by sediments in long-duration ( 7 wk) incubation experiments. More recently, Maran et al. (1995) proposed 2 mathematical models for the quantification of the benthic fluxes of various metals in incubations of $15 \mathrm{~d}$ duration. These modelling exercises took into account some of the processes affecting the concentration of trace elements in the benthic chamber, mainly the process of advective transport due to the sedimentation of suspended matter and sorption/desorption between the solid and liquid phases. Employing empirical methods, other authors (e.g. Forja et al. 1994) have used non-linear regressions between the concentration and the time, calculating the fluxes from the derivative, at zero time, of $C=f(t)$.

The results obtained by Hall et al. (1989) have demonstrated that the use of linear regressions between $C$ and $t$ can significantly underestimate the fluxes by as much as $34 \%$.

This paper presents a model for the calculation of the benthic fluxes of nutrients; it takes into account the alteration produced by the presence of the chamber and enables the flux process to be quantified in the absence of any disturbance. This model may be applied to other substances released from the sediment into the water column and it may be used to investigate, as special cases, those situations where the variation in concentration over time can be considered to be linear. Furthermore, if the diffusive fluxes from the gradients of concentration in the interstitial water are calculated simultaneously, the application of the model enables the thickness of the sediment-water interface to be estimated. This paper adopts the term 'diffusive boundary layer' (DBL) (Gundersen \& Jørgensen 1990) for the liquid stagnancy film existing between the surface of the sediment and the supernatant water, in which advective transport predominates. Nevertheless, no distinction is made between the terms 'sublayer' and 'interface', which are used synonymously.

\section{MATERIAL AND METHODS}

Sampling. The fluxes across the sediment-water interface were measured using benthic chambers; these have been described in detail in a previous paper (Gómez-Parra \& Forja 1992). Briefly, they are constructed of opaque plexiglass and are ellipsoid in shape, with a circular base which covers an area of 
sediment of $0.385 \mathrm{~m}^{2}$ The volume of each chamber varies between 59.1 and $89.8 \mathrm{l}$, depending on the excentricity of the ellipsoid. The choice of chamber size to be used at each site was made on the basis of the expected magnitude of the fluxes

The chamber design featured a recirculation pump which took water from the top and returned it at 3 points situated 3 to $7 \mathrm{~cm}$ above the base; the wide-range variable flow rate of the pump enables the natural currents existing close to the sea floor to be simulated. The current flow rate was measured some 10 to $20 \mathrm{~cm}$ above the floor level just before the positioning of the chamber. Water sampling from inside the chamber was conducted continuously, by means of a peristaltic pump situated on the sea surface. At pre-set intervals of time (usually every $5 \mathrm{~min}$ ), a fraction collector took a sample of $5 \mathrm{ml}$ from the outflow for analysis of nutrients. Samples intended for measurement of the inorganic carbon concentration $(50 \mathrm{ml})$, as well as samples of water from outside the chamber, were taken every $30 \mathrm{~min}$. The dilution produced by the sampling was between 3 and $5 \%$ of the total volume of the chambers. In all cases, samples were conserved at $4^{\circ} \mathrm{C}$ until the time of analysis.

The sediment cores were taken by means of a gravity corer of $40 \mathrm{~mm}$ inner diameter, and were transported refrigerated to the laboratory within $3 \mathrm{~h}$. Interstitial water was obtained from $1 \mathrm{~cm}$ thick 'slices' of the core, after centrifugation at $24000 \times g$ for $30 \mathrm{~min}$. By means of this procedure, it was possible to extract between 74 and $83 \%$ of the total water content of the sediment, depending on the granulometry. Core transportation and subsequent treatment were performed in a nitrogen atmosphere.

The sediment samples for the macrofauna count were taken by means of a Van Veen grab of $240 \mathrm{~cm}^{2}$; the total area sampled was variable, depending on the density of the organisms present, although, in all cases, it was more than $0.15 \mathrm{~m}^{2}$. The sediment samples were sieved fresh, using a $900 \mu \mathrm{m}$ sieve.

Analysis. Nutrient analysis was performed in a TRAACS 800 Technicon autoanalyzer. Total alkalinity and concentration of inorganic carbon were determined by potentiometric titration; in the case of samples of interstitial water, the influence of the principal acid-base systems present was evaluated (GómezParra \& Forja 1994).

Study area and sampling sites. The Bay of Cádiz (SW Spain) is a temperate, shallow-water coastal ecosystem of high productivity generated by high irradiation ( $\left.3244 \mathrm{~h} \mathrm{yr}^{-1}\right)$, high average temperatures (18.4 \pm $6.8^{\circ} \mathrm{C}$ ), and extremely large anthropogenic inputs of organic matter. The hydrodynamics of the zone are very complex, and this results in the presence of a wide variety of sedimentary environments in spite of the zone's relatively small area $\left(40 \mathrm{~km}^{2}\right)$. At the 4 locations shown in Fig. 1, sampling stations were established. In choosing their locations, 2 factors were considered: (1) sediment composition, in terms of granulometry and organic matter input; (2) tidal current speed.

Stn $\mathrm{PR}$ is located in the intertidal zone, but the sea floor, which is mainly argillaceous, is only exposed during spring tides. Stn LC is at an average depth of $8.5 \mathrm{~m}$ and is subjected to a system of strong tidal currents, whose speed is sometimes more than $1.5 \mathrm{~m} \mathrm{~s}^{-1}$ at the surface; the sediment here is silty-clay, with abundant quantities of shell debris of small bivalves. Stn A.S is situated in a secondary channel of the salt-marshes to the south of the Bay; here the currents are slowest and the sediment shows a very fine granulometry. $\mathrm{Stn} \mathrm{BN}$ is at the greatest depth, of around $14 \mathrm{~m}$, and is
Fig. 1. Locations of sampling stations selected in the Bay of Cádiz (SW Spain)

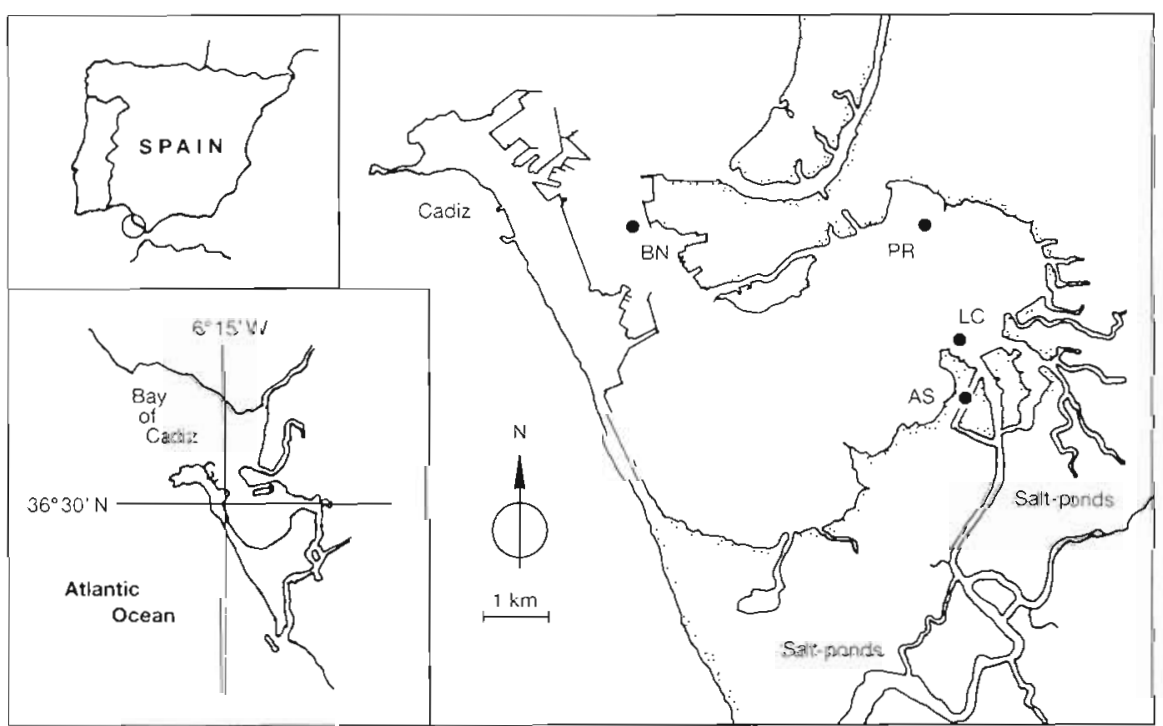


close to the effluent outlet of the treated urban waste waters from a town of some 30000 inhabitants; these waters also support intense maritime traffic. Table 1 summarizes the main characteristics of the sediments at these sampling stations and gives the density and composition of the macrofauna present. The samplings, between 3 and 5 per station, were carried out during the summers of 1989 and 1990.

\section{RESULTS AND DISCUSSION}

In the absence of factors affecting the diffusion, the fluxes measured with benthic chambers $(J)$ should coincide with the diffusive fluxes calculated by means of the vertical gradients in the interstitial water $\left(J_{D}\right)$. But this generally is not so, and the ratio of the 2 magnitudes $\left(A=J / J_{D}\right)$ has been used as a measure of the enhancement of the fluxes as a result of the irrigation processes basically due to the action of the infauna (Smith 1974, Flint \& Kamykowski 1984, Vetter \& Hopkinson 1985, Doering et al. 1987, Dollar et al. 1991, Hargrave et al. 1993, Tahey et al. 1994).

\section{The model}

It may be proposed that inside a benthic chamber the diffusive flux is independent of the activity of the macrofauna and is produced as a result of the existence of a vertical variation in the concentration of the species under study such as that indicated in Fig. 2. The model represented in the figure is based on the following assumptions: (1) it is considered that in the interface between the sediment and the water the concentration of the species being diffused varies linearly across the full thickness of the interface $\left(z_{\mathrm{e}}\right) ;(2)$ during the incubation, the vertical profile of concentration in the interstitial water and, with it, the value of the concentration on the top limit of the sediment (a) remain invariant during the period of time the chamber is in position on the sea floor; under these circumstances, the value of the gradient across the interface determines, at each moment, the rate of the overall process of diffusion; (3) the action of infauna

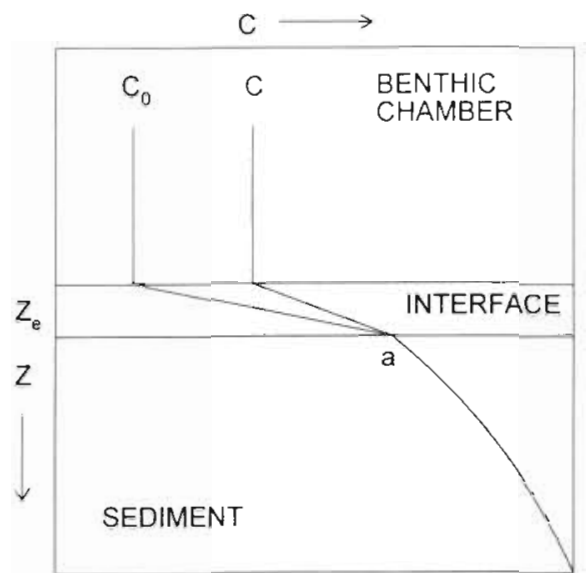

Fig. 2. Evolution of the concentration $(C)$ of nutrients inside the benthic chambers and in the sediment-water interface (bases for the model proposed for the quantification of benthic fluxesl. $a$ and $C_{10}$ : concentrations at lower and upper limits. respectively, of interface at the moment the chamber is put into position; $z$ : depth; $z_{\mathrm{e}}$ : thickness of interface

constitutes the only factor which could affect the diffusive fluxes.

The model also assumes that the water contained within the chamber is sufficiently agitated for us to consider that the concentration is uniform throughout its entire volume. It is implicit, too, that the agitation of the incubated water reproduces the natural currents close to the sea floor, so that the thickness of the interface does not show any change during the time the chamber is in position.

Considering the definition of the flux of matter across a surface, and that the value of the diffusive flux $\left(J_{D}\right)$ is given by the first law of Fick, the total flow $(J)$ can be described as follows:

$$
J=\left(\frac{1}{S}\right)\left(\frac{\mathrm{d} m}{\mathrm{~d} t}\right)=A J_{\mathrm{D}}=A D_{\mathrm{s}} \phi\left(\frac{\partial C}{\partial z}\right)
$$

where $S$ is the area of sediment covered by the chamber; $A$ may be considered as a coefficient related to the activity of the benthic macrofauna; $D_{s}$ is the coefficient of diffusion of the species under study; $\phi$ is the porosity at the interface; and $\partial C / \partial z$ is the concentration gradient across the sediment-water interface.

Table 1. Concentration of organic carbon $(O C)$ and porosity $(\phi)$ in surface sediments at the 4 sampling stations selected in the Bay of Cádiz; the total density and structure of the benthic macrofauna are included

\begin{tabular}{|lccccccc}
\hline Stn & OC $(\%)$ & $\phi$ & Polychaeta $\left(\mathrm{m}^{-2}\right)$ & Bivalvia $\left(\mathrm{m}^{-2}\right)$ & Gastropoda $\left(\mathrm{m}^{-2}\right)$ & Crustacea $\left(\mathrm{m}^{-2}\right)$ & Macrofauna $\left(\mathrm{m}^{-2}\right)$ \\
\hline PR & 3.06 & 0.763 & $1022 \pm 95$ & $20 \pm 12$ & $53 \pm 17$ & - & $1095 \pm 124$ \\
LC & 2.93 & 0.730 & $874 \pm 71$ & $176 \pm 38$ & $431 \pm 46$ & $31 \pm 15$ & $1512 \pm 170$ \\
AS & 2.87 & 0.776 & $889 \pm 40$ & $118 \pm 22$ & $14 \pm 14$ & - & $1021 \pm 76$ \\
BN & 2.16 & 0.723 & $833 \pm 51$ & $209 \pm 27$ & $194 \pm 32$ & $42 \pm 6$ & $1278 \pm 116$ \\
\hline
\end{tabular}


Taking into account the preceding assumptions and accepting, also, that the volume of water in the chamber remains constant during the incubation, the following is obtained:

$$
J=R\left(\frac{\mathrm{d} C}{\mathrm{~d} t}\right)=A D_{\mathrm{s}} \phi\left(\frac{a-C}{z_{\mathrm{e}}}\right)
$$

where $R$ is the ratio between the volume and the surface area covered by the chamber (V/S), and $a$ is the concentration of the species diffused from the layer of interstitial water closest to the sediment surface, which is assumed to remain constant during the period of time of the incubation.

By integrating Eq. (2), one obtains:

$$
C=a-b \exp (-k t)
$$

where $b$ is the difference of concentration between the lower and upper limits of the interface at the moment when the chamber is put into position $\left(a-C_{0}\right)$ and $k$ is equal to $A D_{\mathrm{s}} \phi / R z_{\mathrm{e}}$. The porosity at the interface is taken as equal to unity.

This variation in the concentration over time complies with the limit conditions of $C=C_{0}$ for $t=0$, and $C=a$ for $t=\infty$, which is the maximum value that can be reached in the interior of the chamber. Differentiating Eq. (3) with respect to time, an expression for the flux is given by:

$$
J=R b k \exp (-k t)
$$

This shows that the flux decreases exponentially with time, as a result of the disturbance introduced by the presence of the chamber. Considering its value for $t=0$, which corresponds to the moment before any alteration has been introduced in the system, the following is obtained:

$$
J=R b k
$$

Thus, the flux is obtained from the value of $R$ (which depends on the design of the chamber) and from the values of $b$ and $k$ (which are obtained as parameters of fit of Eq. 3). Taking account of the components of $b$ and $k$, the flux will be given by:

$$
J=A D_{5} \phi \frac{\left(a-C_{0}\right)}{z_{\mathrm{e}}}
$$

The result, logically, is that the flux is independent of the characteristics of the measuring equipment $(R)$ and that its value is given by the gradient assumed to exist under natural conditions, multiplied by a factor $(A)$ which is related to the enhancement of the fluxes by the action of the infauna.

Considering that $k$ can be obtained as the adjustment parameter of the experimental data through Eq. (3), the value of $z_{\mathrm{e}}$ may be ascertained if the value of $A$ is known.
The model includes, as special cases, those situations in which a linear fit between concentration and time is acceptable. In effect, if the exponential in Eq. (3) is substituted by its development in series, the following is obtained:

$$
\begin{aligned}
& C= \\
& a+b k t-\left(\frac{b k^{2}}{2 !}\right) t^{2}+\left(\frac{b k^{3}}{3 !}\right) t^{3}-\ldots+(-1)^{\mathrm{n}+1}\left(\frac{b k^{\mathrm{n}}}{\mathrm{n} !}\right) t^{\mathrm{n}}
\end{aligned}
$$

For low values of $t$ and $k$, the terms $t^{2}$ and greater powers of $t$ can be ignored, and hence the flux, which would then be independent of time, would be obtained from the slope of the straight line $C$ versus $t(J=R b k)$. This would be the case for experiments of very short duration times, or, bearing in mind the elements of $k$, in those situations in which the species being diffused is not very mobile, in which the alteration due to macrofaunal action is very small or when a slow current speed close to the sea floor results in a relatively large thickness for the interface; in short, whenever the fluxes are relatively low and/or their repercussions inside the chamber are relatively small.

The dimensions of the chamber, which determine the value of $R$, may be selected within a wide range, although there are clearly practical factors limiting these dimensions. Thus, the smallest area of sediment surface to be covered by the chamber is effectively determined by the minimum sampling area representative of the sediment composition, which may need to be large in littoral systems. The volume of water incubated is also limited by the need for the chamber to be manageable and by the feasibility of achieving, over a reasonably short period of time, measurable variations in concentration inside the chamber.

\section{Experimental data}

In Fig. 3 the variations of the concentrations of $\mathrm{NH}_{4}^{+}$, $\mathrm{HPO}_{4}{ }^{2-}$, and $\mathrm{SiO}_{2}$ are shown for 2 of the samplings conducted in which the variation of $C$ over $t$ diverges significantly from linearity. The values of the concentration represented here were corrected to take account of the concentration in the water outside the chamber during the sampling period. The coefficients of correlation for the fit of the experimental data to the model (Eq. 3) were above 0.98 in all cases. The use of a linear relationship between $C$ and $t$ results in an underestimation of flux rates which can be relatively high. In our case, for the sampling shown in Fig. 4 (sample A), the degree of error reached $60 \%$ or more.

In Table 2 the average fluxes of ammonia, phosphate, silicate and inorganic carbon at the 4 sampling stations are shown. These values can be considered high as a result of the high content of metabolizable 
A
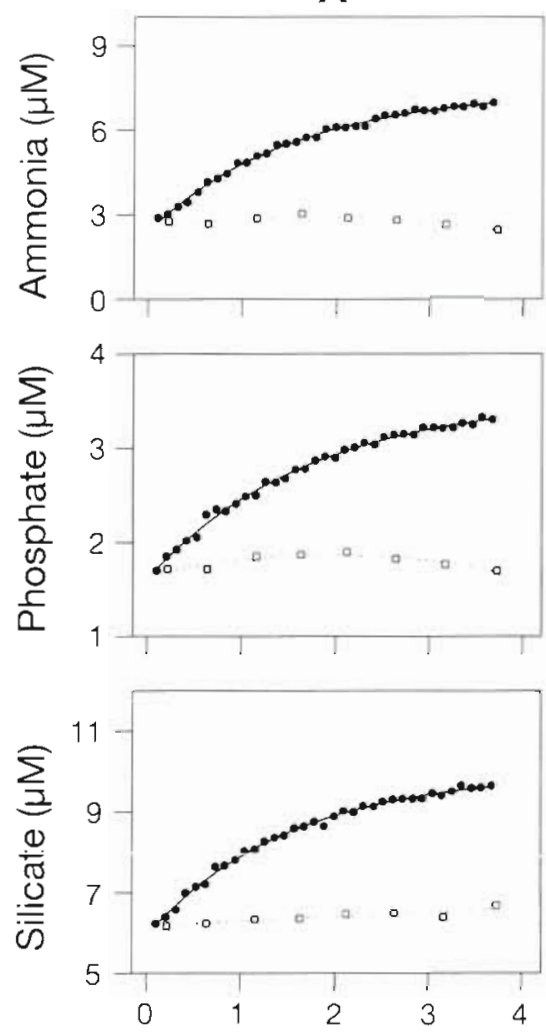

B
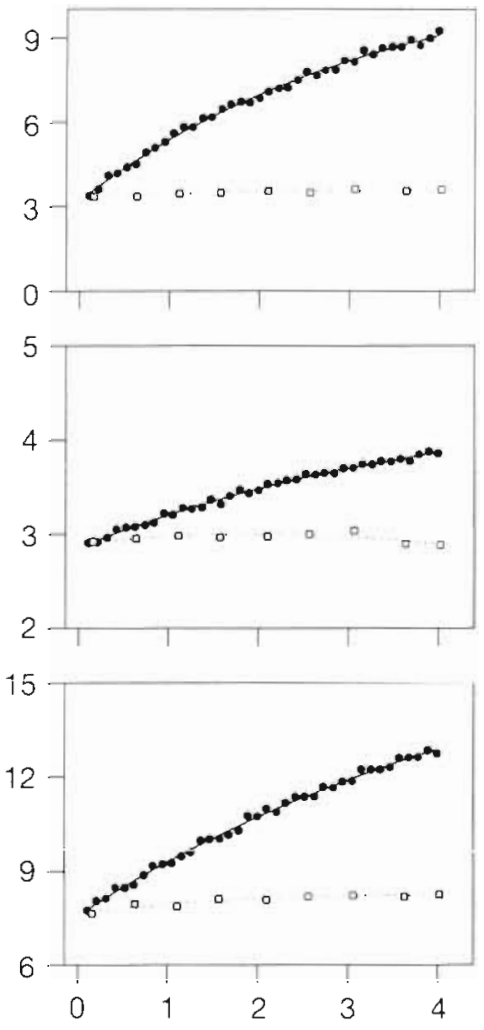

Time (h)

Fig. 3. Variations of the concentration of ammonia, phosphate and silicate inside (solid line) and outside (dashed line) the benthic chambers. The 2 cases shown ( $A$ and $B$ ) are those in which the curvature of the representation of $C$ vs $t$ is particularly intense

organic matter in the sediment of the zone and its intense mineralization during the summer (GómezParra \& Forja 1993, Forja et al. 1994). Nevertheless, other authors have found higher values in other littoral ecosystems (Hall et al. 1992, López et al. 1995)

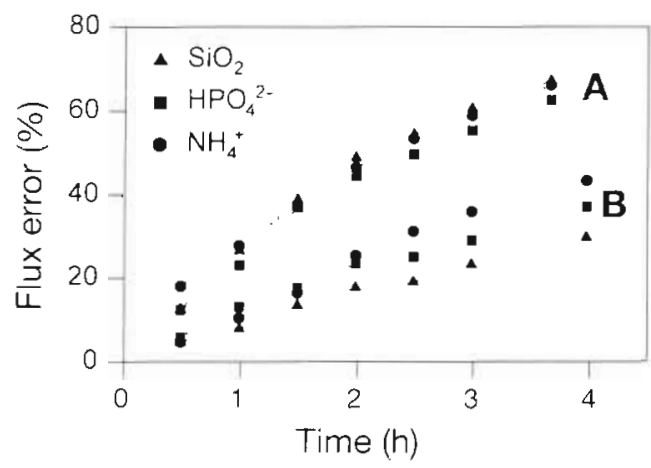

Fig. 4. Degrees of errors recorded in the quantification of benthic fluxes when linear fits as a function of incubation time are used for the 2 samplings (A, B) illustrated in Fig. 3

\section{Verisimilitude of the model}

In general, the assumptions on which the model is based are true. In spite of various authors' views that the concept of a stagnant film through which ions pass by molecular diffusion should be considered to be a convenience, and not a real phenomenon (e.g. Santschi et al. 1983), the studies by Jørgensen \& Revsbech (1985) and later by Gundersen \& Jørgensen. (1990) proved the existence of a DBL, both with incubated cores in the laboratory and with measurements in situ. These studies also showed that in one part of this interface the variations in concentration are linear. This is equivalent to saying that the thickness $z_{\text {e }}$ proposed in our model corresponds to an effective thickness of this interface; this would be that thickness which, by maintaining a constant gradient, would present the same opposition to flow as the real stagnant film. Gundersen \& Jørgensen (1990) also showed that, on a very small scale, 'the sediment surface resembles a rugged landscape of mountains and valleys over which the DBL is spread with a thickness that varies from one point to another by up to a factor of $3^{\prime}$ Given this, the magnitude proposed for the thickness of the interface $\left(z_{\mathrm{e}}\right)$ should be understood as operative, representing the average value over the entire area of sediment covered by the chamber during the period of time it is in position.

The maintenance of a constant concentration in the interstitial water during the period of incubation is not rigorously certain. A reduction of the gradient of concentration in the interface causes the quantity of solute that is transferred from the sediment to the water inside the chamber to decrease over time. This in turn causes the solute to accumulate in the interstitial water, which modifies the value of a. A precise treatment of the problem to enable the variation of a to be obtained is complex, since it implies knowing the evolution of the vertical gradient of concentration in the interstitial water during the period of time the chamber is in position. Nevertheless, an approximate calculation of the variation of a can be made if it is assumed that the rate of production of the species under study in the sediment does not vary, nor does the quantity of this substance that remains adsorbed by the sediment. Both of the above assumptions are acceptable, since 
Table 2. Average values and standard deviations of the in situ $(J)$ and diffusive $\left(J_{D}\right)$ fluxes of ammonia, phosphate, silicate and inorganic carbon. The value of the ratio between these values $\left(A=J / J_{D}\right)$ and the thickness of the interface $\left(z_{\mathrm{e}}\right)$ calculated from the model proposed (see text) are included

\begin{tabular}{|c|c|c|c|c|c|c|}
\hline Stn & $n$ & Substance & $\begin{array}{c}J \\
\left(\mathrm{mmol} \mathrm{m}{ }^{-2} \mathrm{~d}^{-1}\right)\end{array}$ & $\begin{array}{c}J_{D} \\
\left(\mathrm{mmol} \mathrm{m} \mathbf{m}^{-2} \mathrm{~d}^{-1}\right)\end{array}$ & $A$ & $\begin{array}{c}Z_{\mathrm{e}} \\
(\mathrm{mm})\end{array}$ \\
\hline PR & 5 & $\begin{array}{l}\text { Ammonia } \\
\text { Phosphate } \\
\text { Silicate } \\
\text { Inorganic carbon }\end{array}$ & $\begin{aligned} 17.8 & \pm 1.7 \\
6.3 & \pm 0.9 \\
14.4 & \pm 0.5 \\
209.4 & \pm 12.6\end{aligned}$ & $\begin{array}{r}3.14 \pm 0.26 \\
0.50 \pm 0.03 \\
0.66 \pm 0.02 \\
11.62 \pm 0.73\end{array}$ & $\begin{array}{r}5.7 \pm 1.0 \\
12.6 \pm 2.6 \\
21.8 \pm 1.2 \\
18.0 \pm 2.2\end{array}$ & $\begin{array}{l}0.51 \pm 0.14 \\
0.46 \pm 0.16 \\
0.61 \pm 0.05 \\
0.48 \pm 0.09\end{array}$ \\
\hline LC & 5 & $\begin{array}{l}\text { Ammonia } \\
\text { Phosphate } \\
\text { Silicate } \\
\text { Inorganic carbon }\end{array}$ & $\begin{array}{r}19.6 \pm 1.3 \\
5.2 \pm 0.7 \\
18.5 \pm 1.4 \\
198.1 \pm 9.8\end{array}$ & $\begin{array}{l}1.76 \pm 0.20 \\
0.22 \pm 0.05 \\
0.60 \pm 0.04 \\
8.69 \pm 0.85\end{array}$ & $\begin{array}{l}11.1 \pm 2.0 \\
23.1 \pm 5.8 \\
31.0 \pm 3.9 \\
22.8 \pm 3.4\end{array}$ & $\begin{array}{l}0.40 \pm 0.10 \\
0.36 \pm 0.14 \\
0.56 \pm 0.11 \\
0.43 \pm 0.09\end{array}$ \\
\hline AS & 3 & $\begin{array}{l}\text { Ammonia } \\
\text { Phosphate } \\
\text { Silicate } \\
\text { Inorganic carbon }\end{array}$ & $\begin{aligned} 20.0 & \pm 1.3 \\
2.7 & \pm 0.3 \\
8.0 & \pm 0.4 \\
154.6 & \pm 11.3\end{aligned}$ & $\begin{array}{l}3.75 \pm 0.41 \\
0.19 \pm 0.02 \\
0.63 \pm 0.07 \\
7.05 \pm 0.32\end{array}$ & $\begin{array}{r}5.3 \pm 0.9 \\
14.1 \pm 3.4 \\
12.6 \pm 1.5 \\
21.9 \pm 2.0\end{array}$ & $\begin{array}{l}0.60 \pm 0.14 \\
0.52 \pm 0.19 \\
0.71 \pm 0.10 \\
0.50 \pm 0.08\end{array}$ \\
\hline $\mathrm{BN}$ & 3 & $\begin{array}{l}\text { Ammonia } \\
\text { Phosphate } \\
\text { Silicate } \\
\text { Inorganic carbon }\end{array}$ & $\begin{array}{r}15.1 \pm 1.0 \\
2.5 \pm 0.2 \\
9.9 \pm 0.8 \\
224.5 \pm 7.9\end{array}$ & $\begin{array}{l}1.75 \pm 0.31 \\
0.14 \pm 0.03 \\
0.40 \pm 0.04 \\
9.33 \pm 0.26\end{array}$ & $\begin{array}{r}8.6 \pm 1.2 \\
18.0 \pm 2.7 \\
24.7 \pm 3.6 \\
24.1 \pm 1.0\end{array}$ & $\begin{array}{l}0.40 \pm 0.08 \\
0.36 \pm 0.09 \\
0.64 \pm 0.14 \\
0.37 \pm 0.03\end{array}$ \\
\hline
\end{tabular}

the rate of production depends mainly on the temperature and the concentration of degradable organic matter present in the sediment, neither of which vary appreciably over a short period of time (hours) and because the kinetics of adsorption are usually slow. Under these conditions, it may be considered that the quantity of solute accumulated in the interstitial water is equal to that which has not passed to the supernatant water. This value can be calculated from the difference between experimental values for the concentration inside the chamber and the values that would exist if the flux across the interface were to remain constant. Fig. 5A shows the quantity of $\mathrm{NH}_{4}^{+}, \mathrm{SiO}_{2}$ and $\mathrm{HPO}_{4}{ }^{2-}$ accumulated in the sediment as a function of time for the average values of all the samples taken. If it is considered, arbitrarily, that the thickness of sediment affected by the accumulation is similar to that of the 'zone of bioturbation' (approx. $15 \mathrm{~cm}$ ), the variation of $a$ while the chamber is in position can be estimated; the results are shown in Fig. 5B. The value of a varies exponentially with incubation time to such an extent that, particularly for the more mobile species, like $\mathrm{NH}_{4}{ }^{+}$, this variation with respect to its initial value could reach significant proportions. This is not to question the values of the benthic fluxes, since these are calculated from the empirical fit at time zero, independently of whatever causes affect the curvature of these variations.

With regard to the last of the above-formulated hypotheses, the existence of a uniform concentration inside the chamber, if it is accepted that the mechanism for the agitation of the water being incubated does reproduce the natural currents, there can be no conjecture about any cause of the alteration to the interface and, with it, to the fluxes, other than the biological activity. In any case, the achievement of a uniform concentration inside the chamber is a question that can be verified in the laboratory by measuring the degree of approximation of the chamber to a 'completely mixed tank reactor'. Such laboratory experimentation is carried out by means of stimulus-response techniques, using a colouring agent (eosine) as a tracer (Forja et al. 1990). The results obtained show that the chambers in use were fully mixed in 97 to $99 \%$ of their
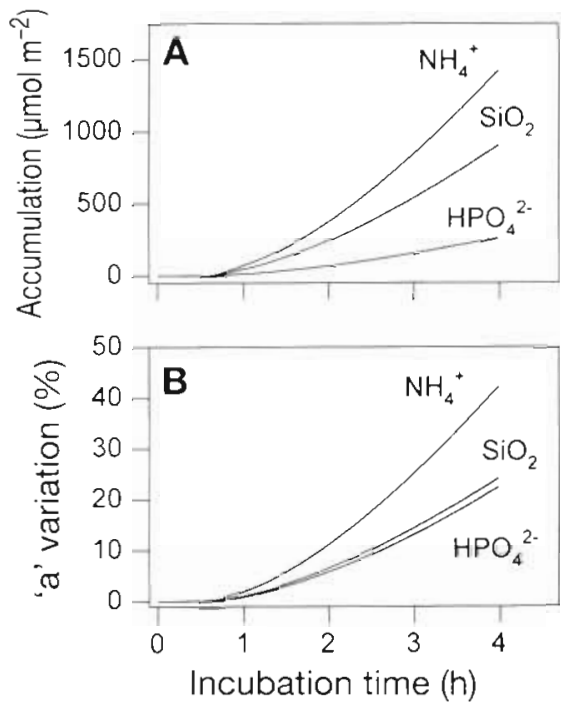

Fig. 5. (A) Accumulation of nutrients in the sediment during a measurement exercise with a benthic chamber. (B) Variation in the concentration of nutrients on the sediment surface (a) as a function of incubation time. The average values of the in situ and diffusive fluxes in the study zone were used for the generation of this graph 
volume, depending on their size and the degree of agitation provided. The samples taken inside the chamber are therefore representative, to these percentages, of the water incubated; therefore the existence of vertical gradients of concentration can be discounted.

The reduction in the concentration of oxygen inside the chambers may potentially affect the metabolism of the aerobic microorganisms and may thus contribute to the non-linearity of the variations of nutrient concentrations over time. This factor has not been taken into account in the model, since the concentration of oxygen did not fall below 150 to $200 \mu \mathrm{M}$ during the time the benthic chambers were on the sea bed. Furthermore, the ratio between the benthic fluxes of inorganic carbon and oxygen in the zone studied shows typical values between 2 and 3 during the summer (Forja et al. 1994). Taking into account that a significant part of the oxygen consumed is due to the oxidation of sulphides (e.g. Jørgensen 1982), the anaerobic oxidation routes for organic matter, basically sulphate reduction, are relatively more important in this zone (Gómez-Parra \& Forja 1993).

\section{Effect of macrofauna on diffusive fluxes}

From the concentration gradients in the interstitial water, the diffusive flux to the overlying water column can be calculated by means of Fick's first law of diffusion:

$$
J_{\mathrm{D}}=\phi D_{\mathrm{s}}\left[\frac{\partial C}{\partial z}\right]_{z=0}
$$

where $J_{\mathrm{D}}$ is the flux across the sediment-water interface, $\phi$ is the porosity in the sediment surface, $D_{\mathrm{s}}$ is the diffusion coefficient in the sediment, and $\partial C / \partial z$ is the gradient of concentration at the sediment surface.

$D_{\mathrm{s}}$ is calculated from the empirical equation of Sweerts et al. (1991):

$$
D_{\mathrm{s}}=D_{0}(-0.73 \phi+2.17)^{-1}
$$

where $D_{0}$ is the diffusion coefficient in water. The $D_{0}$ values established for ammonia and bicarbonate by $\mathrm{Li}$ \& Gregory (1974), for phosphate by Krom \& Berner (1980), and for silicate by Wollast \& Garrels (1971) were used. The value for $\phi$ was obtained by interpolation to zero depth of the exponential fits of porosity with depth.

Figs. 6 \& 7 show some examples of the vertical profiles of concentration found in the interstitial water. In the case of Stns PR and AS, relatively regular variations with depth were found (e.g. Fig. 6), and the gradient of concentration was obtained by means of an. exponential regression of all the experimental data. The existence of a strong irrigation in Stns LC and BN

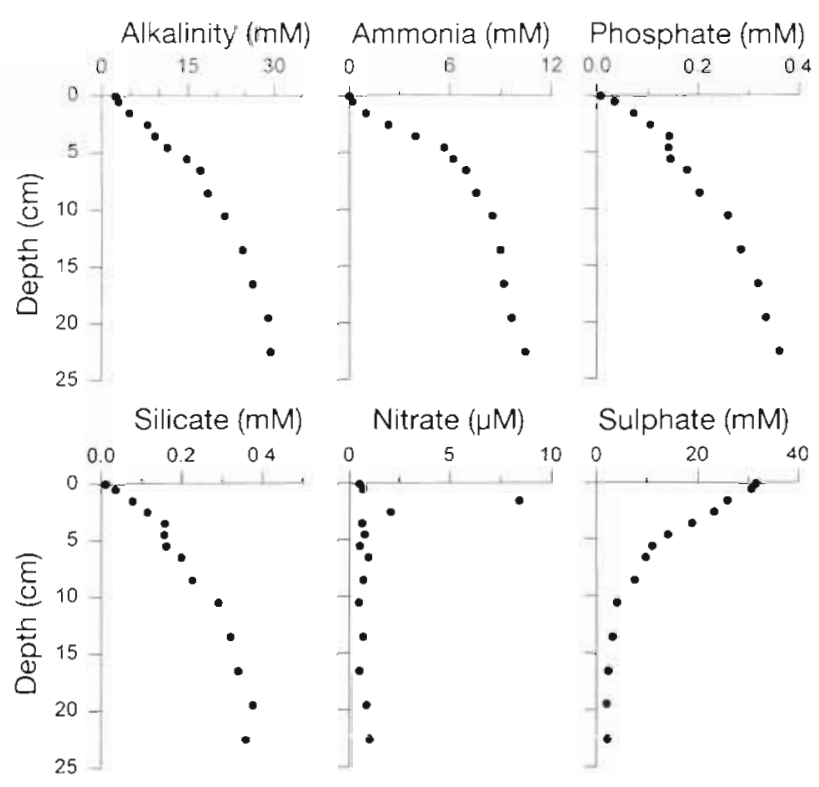

Fig. 6. Vertical variations of alkalinity and of concentration of nutrients and sulphate in the interstitial water for a part of the zone subjected to relatively light irrigation by the benthic macrofauna (PR, July 1990)

resulted in the appearance of a 'zone of bioturbation' in the first 10 to $15 \mathrm{~cm}$ of sediment, characterized by less steep vertical gradients (e.g. Fig. 7). This finding has previously been described in littoral systems close to the zone of our study (Clavero et al. 1991). It can be observed that the processes of irrigation are responsi-

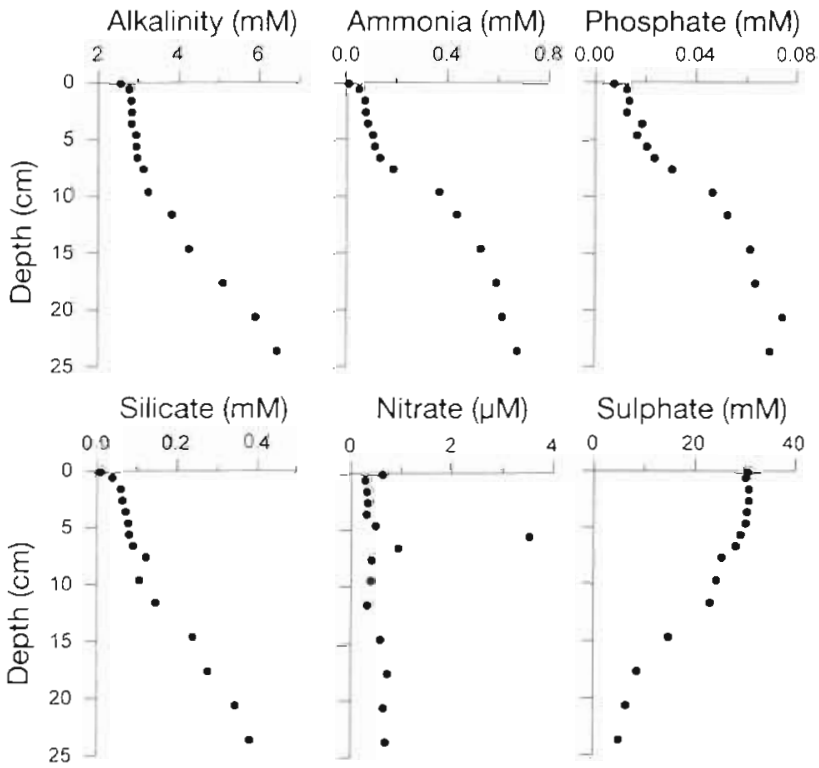

Fig. 7. Vertical variations of alkalinity and of concentration of nutrients and sulphate in the interstitial water for a part of the zone subjected to relatively strong irrigation by the benthic macrofauna (LC., August 1990) 
ble for the appearance of the maximum concentration of nitrate at greater depths in the sediment, and that the concentration of sulphate in the first centimetres of sediment does not vary sharply. Both these facts denote an increase in the thickness of the oxic zone. In these cases, the gradient of concentration at zero depth was obtained by a linear fit in the first centimetres of sediment (Barbanti et al. 1995). There is no unified treatment for the calculation of diffusive fluxes in this type of situation. Some authors obtain the gradient of concentration using the values for depths below the zone of bioturbation (e.g. Krom \& Berner 1980). In accordance with Devol (1987), we have chosen in our study to use exponential fits in the first 5 to $10 \mathrm{~cm}$ of sediment and to include the concentrations in the supernatant water. An additional problem is that the coefficients of diffusion corresponding to zones subjected to irrigation processes are not known; consequently, there is a default error in the quantification of the benthic fluxes (e.g. Goldhaber et al. 1977, Aller 1980, Klump \& Martens 1981, 1989).

The spatial resolution attributable to the data for concentration in the interstitial waters is $1 \mathrm{~cm}$. Because the vertical profiles of concentration on a finer spatial scale are not known, this could result in an underestimation of the diffusive fluxes, particularly when exponential fits are used.

Table 2 shows the values of the diffusive fluxes of ammonia, phosphate, silicate and inorganic carbon, together with the ratio between the in situ and the diffusive fluxes. With regard to the values of $A$, it can be observed that the benthic fluxes of ammonia are affected to a lesser extent by the processes of irrigation of the benthic macrofauna (Callender \& Hammond 1982, Doering et al. 1987). This finding is related to the greater mobility of this ion and to the fact that no processes of adsorption in the sediment take place. In general, the magnitude of $A$ is similar to that described by other authors in different littoral systems; for example, Hopkinson (1987) found values of up to 10.5 for this ratio in the case of ammonia and phosphate, and Rutgers van der Loeff et al. (1984) described values of up to 20 for the ratio between the in situ and diffusive fluxes of silicate.

The elevated values of $A$ found for silicate, up to 31 at Stn LC, are related to the physicochemical nature of the regeneration process of silica, which largely takes place on the surface of the sediment (Lerman 1976). It is in this part of the study zone that the activity of the infauna (meio and macro) is greater, and therefore the effect on this nutrient could be sharper.

The modification produced by the activity of the infauna in a sedimentary environment varies depending on the species present, their density, size and physiological conditions. Although the distribution of species is different at each sampling station, a certain overall dependency was found for the ratio between the in situ and diffusive fluxes on the total density of macrofauna (Fig. 8A). The slope of each of the linear fits represented constitutes a measure of the strengthening of the benthic fluxes through the action of the macrofauna for each nutrient. These slopes vary between $12.4 \times 10^{-3} \mathrm{~m}^{2}$ for ammonia and $32.5 \times 10^{-3} \mathrm{~m}^{2}$ for silicate.

In Table 2 the effective thicknesses estimated for the sediment-water interface from Eq. (6) are also included. Their values (on average $0.45 \mathrm{~mm}$ ) are very close to those described by Jørgensen \& Revsbech (1985) and Gundersen \& Jørgensen (1990) on the Danish coasts, by Santschi et al. (1983) in the Eastern Pacific, and by Devol (1987) in the Aleutian Islands, and slightly lower than those obtained by Sundby et al. (1986) and by Hall et al. (1989).

The range of variation in the estimated thicknesses is wide, between 0.36 and $0.71 \mathrm{~mm}$, depending on the station and the substances used for the calculation. For any one station, the values of $z_{\mathrm{e}}$ calculated from the variations of concentration of ammonia, phosphate, and inorganic carbon show a low spread. The values for the interface thickness obtained from concentrations of silicate are appreciably higher as a result of the greater values of $A$ found for this nutrient.

Fig. $8 \mathrm{~B}$ shows the variation of the average values of $z_{\mathrm{e}}$ at each sampling station, as a function of the density
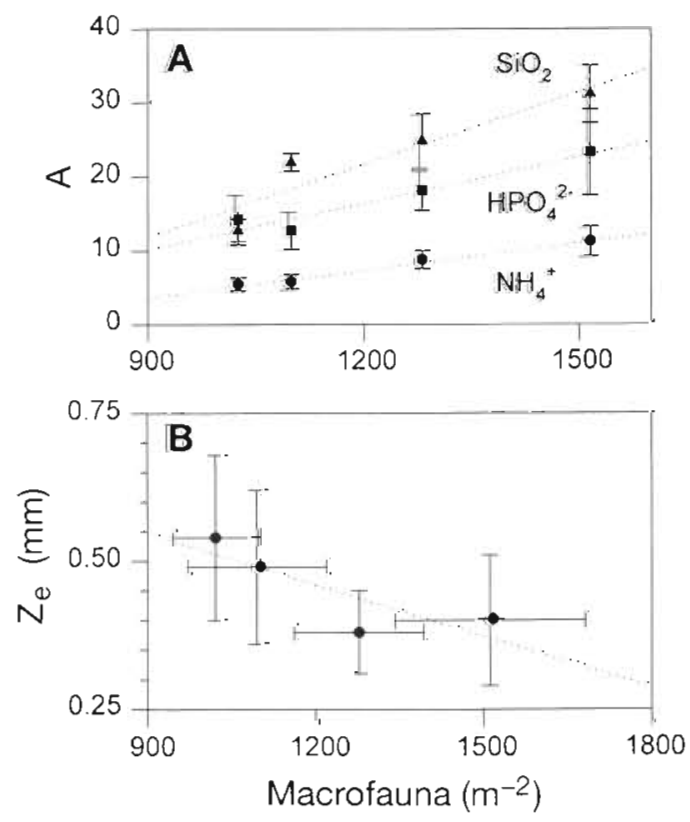

Fig. 8. (A) Dependency of the ratio between the in situ and diffusive fluxes $(A)$ of ammonia, phosphate and silicate on the density of macrofauna. (B) Variation of the thickness of the sediment-water interface as a function of density of macrofauna in the study zone (confidence intervals are SD) 
of macrofauna. Bearing in mind the probabilistic character of the interface thicknesses estimated by this procedure, an increase in the process of irrigation by the infauna translates into a greater alteration of the limiting diffusive layer and, therefore, into a reduction of its thickness.

\section{Final remarks}

In conceptual terms, the use of benthic chambers is responsible for a reduction in the fluxes of substances through the sediment surface incubated. Thus, when ejther the benthic fluxes or the duration of the measurement period is relatively high, non-linear variations of the concentration over time, inside the chamber, are frequently detected. In such cases, the flux can be determined accurately by means of a simple algorithm based on exponential-type variations in the interior of the chamber.

The model proposed is based on the assumption that the flux has an additive character and that it is determined by one term corresponding to the processes of diffusion and another corresponding to the overall effect of the processes of irrigation. These 2 terms are not independent, and it can therefore be assumed that the influence of irrigation on the fluxes is proportional to the vertical gradients of concentration in the interstitial water and therefore to the diffusive fluxes themselves. Under these conditions, a proportionality constant $A$ between the total and the diffusive fluxes can be established.

When the value of $A$ increases, the gradient in the interstitial water decreases, and therefore the use of benthic chambers affects the concentration on the surface of the sediment, which is considered constant in the model. Even in these cases, the values estimated for $z_{\mathrm{e}}$ are similar to those obtained by other techniques in different coastal zones

Within the limitations imposed by the accuracy of the analytical methods used, the choice of a suitable surface-area/volume ratio enables the alteration due to the chamber itself to be reduced. Thus, the unification of the criteria employed in the design of benthic chambers would enable a more homogeneous database to be compiled; this in turn would enable the deeper study of the importance of benthic regeneration in the primary productivity of littoral ecosystems and its transcendant role in the biogeochemical cycles of nutrient elements.

Acknowledgements. The work was supported by the Consejo Superior de Investigaciones Cientificas (C.S.I.C.) through research grant 630/070-1988. We thank M. F. Osta and P, Vidal for their assistance during sampling and analysis.

\section{LITERATURE CITED}

Aller RC (1980) Diagenetic processes near the sedimentwater interface of Long Island Sound. I. Decomposition and nutrient element geochemistry (S, N, P). Adv Geophys $22: 237-350$

Asmus $R$ (1986) Nutrient flux in short-term enclosures of intertidal sand communities. Ophelia 26:1-18

Barbanti A, Bergamini MC, Frascari F, Miserocchi S, Ratta M, Rosso G (1995) Diagenetic processes and nutrient fluxes at the sediment-water interface, Northern Adriatic Sea, ltaly. Mar Freshwat Res 46:55-67

Billen $G$ (1978) A budget of nitrogen cycling in North Sea sediments of the Belgian coast. Estuar Coast Shelf Sci 7: $127-146$

Boynton WR, Kemp WM, Osborne CG (1980) Nutrient fluxes across the sediment-water interface in the turbid zone of a coastal plain estuary. In: Kennedy VS (ed) Estuarine perspectives. Academic Press, New York, p 93-109

Callender E, Hammond DE (1982) Nutrient exchange across the sediment-water interface in the Potomac river estuary. Fstuar Coast Shelf Sri 1.5:395-41.3

Clavero V. Niell FX, Fernández JA (1991.) Effects of Nereıs diversicolor $\mathrm{O}$. F. Muller abundance on the dissolved phosphate exchange between sediment and overlying water in Palmones river estuary (Southern Spain). Estuar Coast Shelf Sci. 33:193-202

Devol AH (1987) Verification of flux measurements made with in situ benthic chambers. Deep Sea Res 34: $1007-1026$

Doering PH, Kelly JR, Oviatt CA, Sowers T (1987) Effect of the hard clam Mercenaria mercenaria on benthic fluxes of inorganic nutrients and gases. Mar Biol 94:377-383

Dollar SJ, Smith SV, Vink SM, Obrebski S, Hollibaugh JT (1991) Annual cycle of benthic nutrient fluxes in Tomales Bay, California, and contribution of the benthos to total ecosystem metabolism. Mar Ecol Prog Ser 79:115-125

Elderfield H, Luedtke N, McCaffrey RJ, Bender M (1981) Benthic fluxes in Narragansett Bay. Am J Sci 281:768-787

Fisher TR, Carlson PR, Barber RT (1982) Sediment nutrient regeneration in three North Carolina estuaries. Estuar Coast Shelf Sci 14:101-116

Flint RW, Kamykowski D (1984) Benthic nutrient regeneration in South Texas coastal waters. Estuar Coast Shelf Sci 18: $221-230$

Forja JM, Blasco J, Gomez-Parra A (1994) Spatial and seasonal variations of 'in situ' benthic fluxes in the Bay of Cádiz (SW Spain). Estuar Coast Shelf. Sci 39:127-141

Forja JM, Romero LI, Gómez-Parra A (1990) Benthic chambers to measure nutrient fluxes across the sediment-water interface as a biochemical reactor. 5th Mediterranedn Congress on Chemical Engineering, Barcelona (Spain) $2: 546-547$

Goldhaber MB, Aller RC, Cochran JK, Rosenfeld JK, Martens CS, Berner RA (1977) Sulfate reduction, diffusion, and bioturbation in Long Island Sound sediments: report of the FOAM group. Am J Sci 277:193-237

Gómez-Parra A, Forja JM (1992) Significance of benthic regeneration in nutrient balance in the Bay of Cádi\%, south-west Spain la shallow semi-closed coastal ecosystem). Sci Total Environ Suppl 1992:1079-1086

Gómez-Parra A, Forja JM (1993) Nutrient benthic fluxes in Cádiz Bay (S.W. Spain). Hydrobiologia 252:23-34

Gómez-Parra A, Forja JM (1994) An operative definition of alkalinity in interstitial water. Mar Chem 45:53-65

Gundersen JK, Jørgensen BB (1990) Microstructure of diffusive boundary layers and the oxygen uptake of the sea 
floor. Nature 345:604-607

Hall POJ, Anderson LG, Rutgers van der Loeff MM, Sundby B. Westerlund SFG (1989) Oxygen uptake kinetics in the benthic boundary layer Limnol Oceanogr 34(4):734-746

Hall POJ, Holby O, Kollberg S, Samuelsson MO (1992) Chemical fluxes and mass balances in a marine fish cage farm. IV. Nitrogen. Mar Ecol Prog Ser 89:81-91

Hargrave BT, Duplisea DE, Pfeiffer E, Wildish DJ (1993) Seasonal changes in benthic fluxes of dissolved oxygen and ammonium associated with marine culture Atlantic salmon. Mar Ecol Prog Ser 96:249-257

Hopkinson CS (1987) Nutrient regeneration in shallow-water sediments of the estuarine plume region of the nearshore Georgia Bight, USA. Mar Biol 94:127-142

Jørgensen BB (1982) Mineralization of organic matter in the sea-bed. The role of sulphate reduction. Nature 296: $643-645$

Jorgensen BB, Revsbech NP (1985) Diffusive boundary layers and the oxygen uptake of sediments and detritus. Limnol Oceanogr 30(1):111-122

Kautsky N, Wallentinus I (1980) Nutrient release from a Baltic Mitylus-red algal community and its role in benthıc and pelagic productivity. Ophelia Suppl 1:17-30

Klump JV, Martens CS (1981) Biogeochemical cycling in an organic rich coastal marine basin. II. Nutrient sedimentwater exchange processes. Geochim Cosmochim Acta 45: $101-121$

Klump JV, Martens CS (1989) The seasonality of nutrient regeneration in an organic-rich coastal sediments: kinetic modeling of changing pore-water nutrient and sulfate distributions. Limnol Oceanogr 34(3):559-577

Krom MD, Berner RA (1980) Adsorption of phosphate in anoxic marine sediments. Limnol Oceanogr 25 $797-806$

Lerman A (1976) Migrational processes and chemical reactions in interstitial waters. In: Goldberg ED, McCave IN, O'Brien JJ, Steele JH (eds) The sea, Vol 6. Wiley, New York, p 695-738

Li YH, Gregory S (1974) Diffusion of ions in seawater and in deep sea sediments. Geochim Cosmochim Acta 40: $257-266$

López P, Vidal M, Lluch X, Morguí JA (1995) Sediment metabolism in a transitional continental/marine area: the Albufera of Majorca (Balearic Islands, Spain). Mar Freshwat Res 46:45-53

Malan DE, McLachlan A. (1991) In situ benthic oxygen fluxes in a nearshore coastal marine system: a new approach

Editorial responsibility: Otto Kinne (Editor).

Oldendorf/Luhe, Germany to quantify the effect of wave action. Mar Ecol Prog Ser 73:69-81

Maran S, Ciceri G, Martinotti W (1995) Mathematical models for estimating fluxes at the sediment-water interface in benthic chamber experiments. Hydrobiologia 297:67-74

Matsukawa Y, Sato Y, Sasaki K (1987) Benthic flux of nutrient salts on an intertidal flat. Nippon Suisan Gakkaishi 53(6): 985-989

Rowe GT, Clifford CH, Smith KL, Hamilton PL (1975) Benthic nutrient regeneration and its coupling to primary productivity in coastal waters. Nature 255:215-217

Rutgers van der Loeff MM, Anderson LG, Hall POJ, Iverfeldt $\AA$, Josefson AB, Sundby B, Westerlund SFG (1984) The asphyxiaton technique: an approach to distinguishing between molecular diffusion and biologically mediated transport at the sediment-water interface. Limnol Oceanogr 29(4):675-686

Santschi PH, Bower P, Nyffeler UP, Azevedo A, Broecker WS (1983) Estimates of the resistance to chemical transport posed by the deep-sea boundary layer. Limnol Oceanogr 28(5):899-912

Smith KL (1974) Oxygen demands of San Diego trough sediments: an in situ study. Limnol Oceanogr 19(6):939-944

Smith KL, Laver MB, Brow NO (1983) Sediment community oxygen consumption and nutrient exchange in the central and eastern North Pacific. Limnol Oceanogr 28(5):882-898

Sundby B, Anderson LG, Hall POJ, lverfeld $\AA$, Rutgers van der Loeff MM. Westerlund SFG (1986) The effect of oxygen on release and uptake of cobalt, manganese, iron and phosphate at the sediment-water interface. Geochim Cosmochim Acta 50:1281-1288

Sweerts JPRA, Baer-Gilissen MJ, Cornelese AA (1991) Oxygen-consuming processes at the profundal and littoral sediment-water interface of a small meso-eutrophic lake (Lake Vechten, The Netherlands). Limnol Oceanogr 36: 1124-1133

Tahey TM, Duineveld GCA, Berghuis EM, Helder W (1994) Relation between sediment-water fluxes of oxygen and silicate and faunal abundance at continental shelf, slope and deep-water stations in the northwest Mediterranean. Mar Ecol Prog Ser 104:119-130

Vetter EF, Hopkinson CS (1985) Influence of white shrimp (Penaeus setiferus) on benthic metabolism and nutrient flux in a coastal marine ecosystem: measurements in situ. Contrib Mar Sci 28:95-107

Wollast R, Garrels RM (1971) Diffusion coefficient of silica in seawater. Nat Phys Sci 229:94

Submitted: May 9, 1997; Accepted: February 11, 1998

Proofs received from author(s): March 19, 1998 